\title{
KAIN TENUN IKAT SEBAGAI MEDIA PEMBELAJARAN IPS DI SEKOLAH DASAR
}

\author{
Oleh:
}

Heronimus Delu Pingge \& Rahel Maga Haingu

STKIP Weetebula

Email: delupingge@stkip-weetebula.ac.id

\begin{abstract}
Abstrak
Kain tenun ikat merupakan warisan budaya, Sumba yang memiliki motif beragam serta memiliki nilai-nilai budaya. Penelitian ini bertujuan, 1) Mengidentifikasi fauna dan flora pada motif kain tenun Sumba Timur sebagai media belajar Ilmu Pengetahuan Sosial (IPS) di Sekolah Dasar (SD). Penelitian ini termasuk jenis penelitian kualitatif deskriptif. Hasil penelitian ditemukan 1) Bahwa pada motif kain ikat Sumba Timur terdapat motif fauna dan flora yang ada disekitar masyarakat. 2) Motif kain ikat Sumba Timur mengambarkan hasil pemikiran, pengalaman, pandangan hidup, ataupun benda-benda yang ada di sekitar para penenun. Dengan motif yang bercorak fauna dan flora dapat dijadikan sebagai media pembelajaran yang kontektual dalam mengajarkan materi fauna dan flora pada matapelajaran Ilmu Pengetahuan Sosial di Sekolah.
\end{abstract}

Kata kunci: kain tenun ikat, media belajar IPS, SD

\section{Abstract}

Kain tenun was cultural heritage of the Sumba Island community, in which has diverse motifs, and cultural values. This research aims to identifying the fauna and flora of East Sumba motif as medium for learning of Social Sciences in Elementary Schools. Research conducted by descriptive qualitative methods. The material of research was kain ikat Sumba Timur. The results of the research were found as follows: 1) East Sumba kain ikat enclosed fauna and flora motifs that from Sumba Islands; 2) the motif kain ikat East Sumba exemplifies of minds, experiences, outlook on life, or objects that are around the weavers. With motifs that are characterized by fauna and flora, it can be used as a contextual learning media in teaching fauna and flora material in social science subjects in elementary schools.

Keywords: kain tenun ikat, social studies media, elementary school. 


\section{Pendahuluan}

Kebudayaan merupakan salah satu anasir identitas manusia yang menempatkan mereka dalam kedudukan tertinggi di muka bumi. Pasal 32 Undang-undang Dasar tahun 1945 menjelaskan bahwa negara Indonesia mendukung kemajuan kebudayaan nasional Indonesia. Pemerintah secara langsung harus mengembangkan potensi yang ada, yang berkaitan dengan kebudayaan itu sendiri, sehingga memperkaya kebudayaan nasional Indonesia (Depdikbud, 1990:1). Tujuan mengembangkan kebudayan dilatarbelakangi oleh kebutuhan untuk menempatkan kebudayaan nasional pada derajat yang tinggi atas dasar pemahaman bahwa kebudayaan nasional, yang menjamin unsur-unsur kebudayaan daerah, merupakan identitas bangsa dan negara yang harus dilestarikan, dikembangkan, dan diteguhkan di tengah perubahan global yang pesat dan dapat mengancam identitas bangsa dan negara Indonesia (Fanpula, 2014).

Salah satu unsur kebudayaan daerah adalah unsur pakaian adat tradisonal. Unsur pakaian adat tradisional dalam kehidupan nyata mempunyai fungsi sesuai pesan-pesan nilai budaya yang terkandung di dalamnya, yang berkaitan dengan aspek-aspek lain dari kebudayaan seperti ekonomi, sosial, politik, keagamanaan, dan pendidikan. Pesan-pesan nilai budaya yang disampaikan, pemahamannya dapat dilakukan dengan melalui berbagai simbol dalam ragam hias atau motif pakaian adat tradisional. Pada saat sekarang motif tersebut mulai dilupakan dan tidak digemari oleh generasi muda.

Pakaian tradisional merupakan pakaian yang digunakan sejak dahulu dalam suatu masyarakat tertentu. Pakaian merupakan salah satu identitas atau salah satu ciri pengenal masyarakat pemakainya. Pakaian tradisional juga disebut sebagai 
pakaian adat. Pakaian adat dipandang sebagai simbol sandang yang mempunyai ciri khas suatu daerah (https://brainly.co.id/), sebagai pakaian rakyat dan atau busana nasional yang mengekspresikan identitas, yang biasanya dikaitkan dengan wilayah geografis atau periode waktu dalam sejarah. Pakaian adat juga menunjukkan status sosial, perkawinan, atau agama (wikipedia, 2019).

Nusa Tenggara Timur (NTT) kaya akan pakaian tradisional yang beraneka ragam, masing-masing daerah atau kabupaten memiliki hasil tenunan dengan beraneka ragam motif sesuai dengan ciri khas dan adat istiadat budaya setempat (Mamulak, 2015: 399). Provinsi NTT terdiri dari 550 pulau dengan tiga pulau besar yakni Palau Timor, Flores dan Sumba serta beberapa pulau lainnya seperti Rote, Sabu, Adonara, Solor, Komodo dan Palue. Dengan Kota Kupang sebagai ibukota provinsi yang terletak di pulau Timor. Pemerintahan di Provinsi NTT terdiri dari 21 Kabupaten, dan 1 Kotamadya. Satu kabupaten memiliki kurang lebih 30 macam motif tenunan yang berbeda-beda keguna-annya karena setiap desa atau suku mempunyai motif sendiri (Mamulak, 2015: 400). Setiap motif tenunan merupakan karya warisan yang syarat akan seni dan pesan para leluhur yang kaya akan makna. Setiap motif merupakan dorongan memvisualisasikan konsepkonsep interaksi di suatu komunitas masyarakat atau relasinya dengan alam natura (dunia fauna dan flora) melahirkan berbagai tanda gambar atau motif pada kain ikat (Hebi, F., 2014: 2).

Masyarakat yang menghuni pulau Sumba sudah sejak lama membuat, memakai, dan memperdagangkan kain tenun ikat/kain Sumba (Ndima 2007: 63). Hingga saat ini kain tenun ikat Sumba sebagai warisan budaya masih tetap bertahan dan berkembang yang bernilai budaya dan ekonomi. Soelarto (1979: 16) 
mengatakan bahwa sumber penghasilan tambahan yang merupakan home industry seluruh lapisan masyarakat ialah pertenunan. Masyarakat Sumba dan kain tenun merupakan dua hal yang tidak dapat terpisahkan, kain tenun tidak hanya sebagai sumber mata pencaharian namun juga menjadi bagian yang selalu hadir dalam aspek kehidupan sehari-hari masyarakat Sumba. Kain Tenun Sumba memiliki warna dan motif yang berbeda-beda antara kabupaten yang satu dengan lainnya.

Di Kabupaten Sumba Barat Daya sendiri terdapat corak warna dan motif kain tenun yang berbeda di setiap suku. Ada tiga suku besar di Sumba Barat Daya, yakni Kodi, Wewewa, dan Laura. Ketiga suku ini memiliki corak warna dan motif kain yang berbeda. Corak warna suku Kodi dominan hitam, Wewewa dan Laura berwarna-warni. Untuk memperjelas uraian, maka berikut ini akan ditampilkan gambar peta Kabupaten Sumba Barat Daya.

Gambar 1. Peta Propinsi Nusa Tenggara Timur

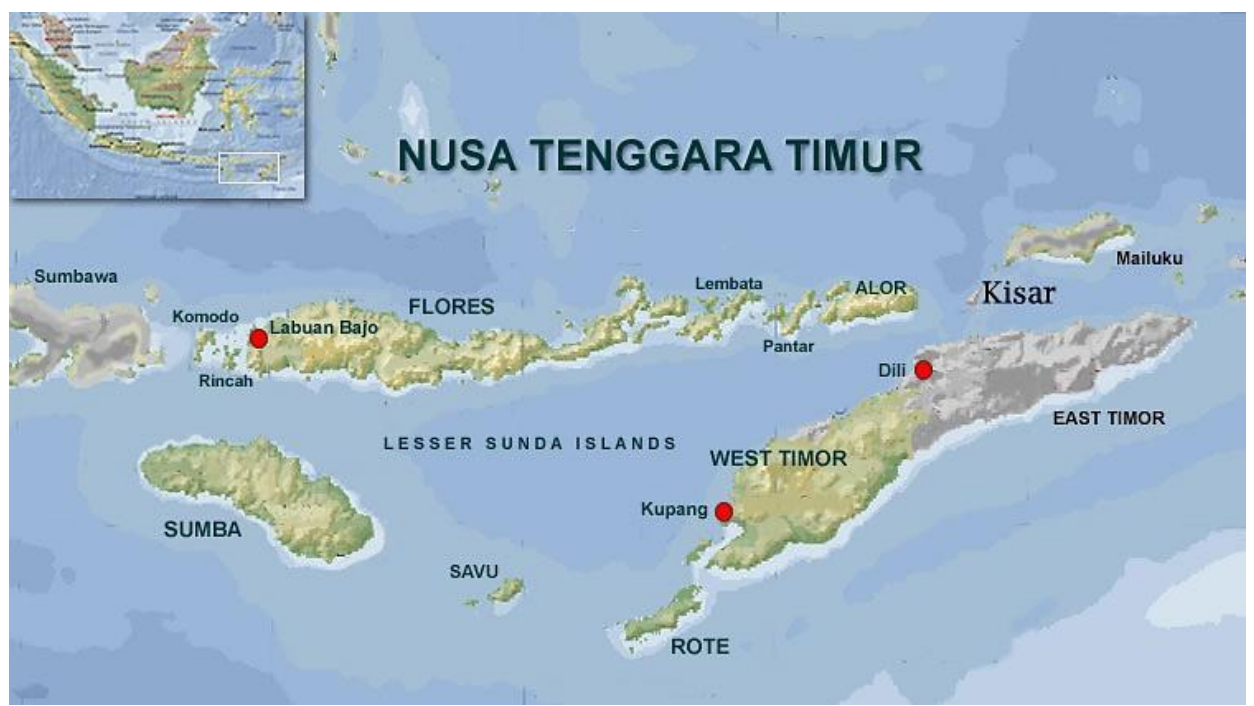

(Gambar dari: www.lavalontouristinfo.com)

Pakaian adat tradisional daerah merupakan salah satu materi dalam pelajaran Ilmu Pengetahuan Sosial (IPS) di Sekolah 
Dasar (SD). Kompetensi dasar "keragaman budaya Indonesia" merupakan salah satu kompetensi yang harus dikuasai oleh peserta didik (Kemendikbud, 2016). Kain tenun juga dapat difungsikan sebagai sumber belajar yang kontekstual. Materi yang lain adalah materi penyebaran fauna dan flora. Ketika mengajar materi tentang keragaman fauna dan flora, maka motif-motif kain adat tradisional yang bercorak fauna dan flora dapat dijadikan sebagai media pembelajaran yang kontekstual.

IPS di SD menekankan pengenalan peserta didik terhadap lingkungannya dengan tujuan agar peserta didik tidak tercerabut dari akar budayanya. Pengenalan lingkungan dan masyarakat diawali dari lingkungan yang terdekat sampai yang terjauh. Pengenalan wilayah lokal, juga harus mampu mengidentifikasi sejumlah nilai kearifan lokal (Kemendikbud, 2016). Nilai-nilai kearifan lokal perlu diintroduksi sejak dini melalui berbagai media dan sarana agar fungsi sekolah sebagai wahana transmisi nilainilai budaya dapat terjadi. Di PAUD Amongsiwi, Bantul, Yogyakarta ditemukan bahwa transmisi nilai kearifan lokal melalui permainan tradisional menghasilkan peningkatan kreativitas peserta didik (Sudrajat, Wulandari, Wijayanti, 2015).

Penggunaan budaya lokal sebagai sumber belajar Ilmu Pengetahuan sosial memfasilitasi peserta didik memahami secara langsung konten materi yang dikorelasikan dengan kondisi kehidupan sehari-hari di sekitar tempat tinggal peserta didik (Mina Holilah, 2015). Dalam konteks tersebut pendidikan IPS di sekolah dasar juga harus mengubah paradigma pembelajaran yang berorientasi kognitif menuju output pembelajaran yang menghasilkan sikap dan perilaku yang relevan dengan perkembangan zaman (Sudrajat, 2014, 12). 
Kurikulum 2013 yang sedang berlaku saat ini. Tema sentral pengembangan Kurikulum 2013 adalah menghasilkan insan Indonesia yang produktif, kreatif, inovatif, melalui penguatan sikap, keterampilan, dan pengetahuan yang terintegrasi (Kemendikbud, 2016). Supaya tujuan tema tersebut dapat terwujud maka satuan pendidikan termasuk Sekolah Dasar (SD) harus menyelenggarakan proses pendidikan secara interaktif, inspiratif, menyenangkan, menantang, dan memotivasi peserta didik untuk berpartisipasi aktif, serta memberikan ruang bagi tumbuhnya prakarsa, kreativitas, dan kemandirian sesuai dengan potensi bakat, minat, dan perkembangan fisik, serta psikologis peserta didik.

Proses pendidikan yang interaktif, inspiratif, menyenangkan, menantang, dan memotivasi peserta didik dapat dirancang dengan memanfaatkan lingkungan sebagai sumber belajar. Lingkungan merupakan sumber belajar kontekstual. Lingkungan yang dimaksud dalam kajian ini adalah lingkungan sosial budaya berupa kearifan lokal yang ada disekitar lingkungan tempat tinggal peserta didik (Pingge, 2019). Motif tenun kain Sumba merupakan salah satu kearifan lokal masyarakat Sumba yang menggambarkan pola pikir dan paradigma masyarakat dalam mengenal dan mengidentifikasi benda-benda dalam konstruk sosial budaya Sasak.

Berkaitan dengan pakaian adat tradisional propinsi NTT yang kaya akan motif pada masing-masing pulau dan kabupaten, maka perlu diindentifikasi motif kain tenun ikat Sumba yang bercorak fauna dan flora untuk dijadikan sebagai media pembelajaran yang kontekstual pada materi persebaran fauna dan flora di Indonesia. Supardi, Widiastuti \& Saliman (2015: 5) menegaskan bahwa dalam penggunaan media diharapkan mampu menarik perhatian siswa 
sehingga dapat memusatkan daya pikir dan perhatian untuk meningkatkan keterlibatan peserta didik dalam pembelajaran. Luasnya materi dan bahan ajar IPS harus menjadikan perhatian bagi guru untuk memilih tema dan materi yang kontekstual dan bermakna. Kain ikat sebagai produk budaya merupakan salah satu faktor positif untuk menjadi media penyampaian informasi kepada peserta didik agar proses tranfer of knowledge menjadi bermakna.

\section{Metode Penelitian}

Penelitian menggunakan penelitian kualitatif dengan pendekatan etnografi. Metode Etnografi digunakan untuk menggambarkan, menjelaskan dan menganalisis unsur kebudaya-an suatu masyarakat atau suku bangsa (Sparadley, 2006: 55). Data dikumpulkan dengan cara wawancara dan dokumentasi. Data yang sudah dikumpulkan divalidasi dengan cara atau teknik triangulasi dengan melakukan cross-check antara data yang diperoleh melalui wawancara maupun dengan dokumentasi.

Setelah semua data diperoleh dari sumber data maka selanjutnya data penelitian tersebut siap untuk diolah, analisis dalam penelitian ini di dalamnya tercakup empat hal pokok yakni pengumpulan data melalui wawancara mendalam (in depth interview) dengan para narasumber serta dokumentasi, reduksi data. Proses pengumpulan data dibantu dengan instrumen berupa panduan wawancara dan check list dokumen yang hendak dikumpulkan.

Peneliti merangkum hasil wawancara dan dokumentasi, dan menentukan garis besarnya. Penyajian data dilakukan dengan memaparkan hasil rangkuman ke dalam kelompok-kelompok motif berdasarkan daerahnya. 


\section{Hasil Penelitian}

Berdasarkan dari hasil penelitian yang dilakukan pada kain tenun ikat Sumba ditemukan motif yang bercorak fauna dan flora. Fauna dan flora yang terdapat pada motif kain Sumba adalah yang ada disekitar atau lingkungan masyarakat Sumba maupun fauna dan flora yang terdapat di Pulau lain, misalnya dari darerah Pulau Jawa dan Sumatra. Terdapatnya motif fauna dan flora dari luar pulau Sumba akibat dari pola interaksi masyarakat Sumba dengan para pedagang dari luar. Bahkan terdapat motif fauna yang ada dilegenda atau budaya negara lain, yakni motif Naga yang dibawah oleh pedagang Cina.

Motif-motif fauna dan flora dibuat oleh para penenun untuk mempunyai makna budaya atau menyampaikan pesan tertentu. Selain itu motif itu juga sebagai hasil kreatif untuk menyampaikan atau menuangkan ide dan pikiran dari para penenun. Secara keseluruhan ada dua puluh empat motif fauna dan flora yang terdapat pada kain tenun ikat Sumba. Motif fauna yang paling banyak digunakan pada kain yakni ada dua puluh fauna atau hewan. Sedangkan motif flora sebanyat empat.

Motif kain yang bercorak fauna tersebut dapat dijadikan sebagai media untuk menyampaikan atau mempelajari materi IPS tentang persebaran fauna dan flora. Hal tersebut dimungkinkan karena kebijakan pemerintah daerah untuk mewajibkan sekolah atau instansi pemerintah untuk menggunakan pakaian daerah pada hari Kamis dan Jumad. Hal tersebut memungkinkan untuk memudahkan siswa mengenal dan mengetahui dengan lebih baik tentang materi pembelajaran tentang fauna dan flora. Dari situlah pembelajaran yang kontekstual yang diharapkan dalam kurikulum 2013 dapat direalisasikan. Setelah diidentifikasi dan dikelompok- 
kan maka dibawah ini akan diuraikan dua puluh empat motif tersebut beserta gambarnya:

\section{1) Motif Udang}

Udang dalam bahasa Sumba adalah kuran atau kurra (Sunba Bagian Barat) merupakan hewan air yang biasa dijumpai pada sungai-sungai kecil di Pulau Sumba ataupun pada kali atau danau dimusim penghujan.

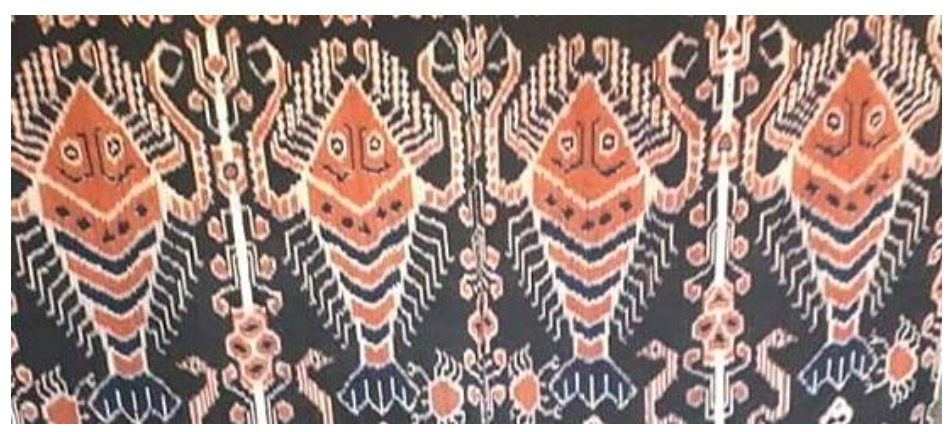

Gambar 2. Motif Udang

\section{2) Motif Penyu}

Penyu sering dijumpai disepanjang bibir pantai Sumba, secara geografis pulau sumba terletak pada garis pantai selatan dari Indonesia.

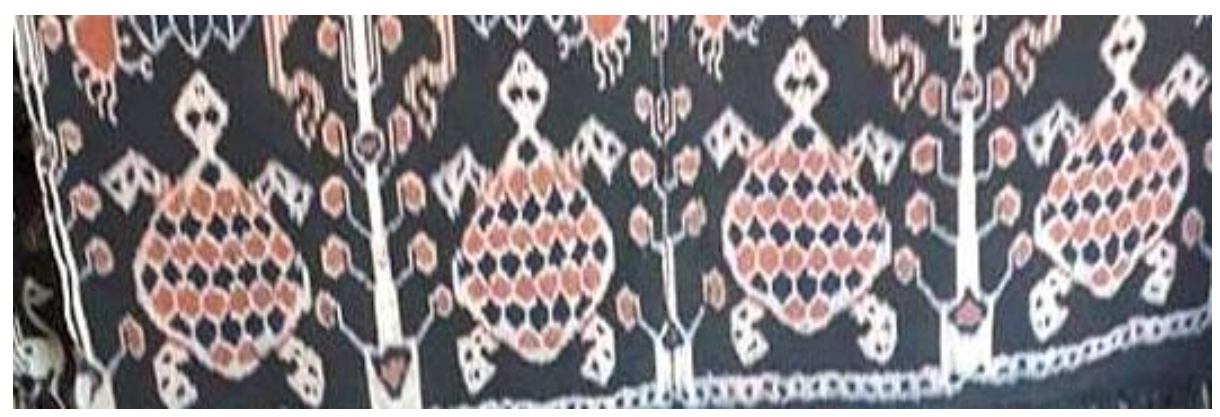

Gambar 3. Motif Penyu

\section{3) Motif Kuda}

Kuda merupakan salah satu ciri khas Pulau Sumba yang memberikan gambaran mengenai karakter masyarakat Sumba 
sebagai peternak kuda. Kuda Sumba tergolong Kuda Sandel yang telah memiliki reputasi tinggi dalam kejuaraan balap kuda yang dikenal dengan perawakannya yang tinggi dan besar. Sering di jumpai dipandang-padang atau sabana. Kuda dipulau Sumba bernilai ekonomi dan budaya selain itu kuda pada jaman dulu dijadikan sebagai alat transportasi masyarakat Sumba.

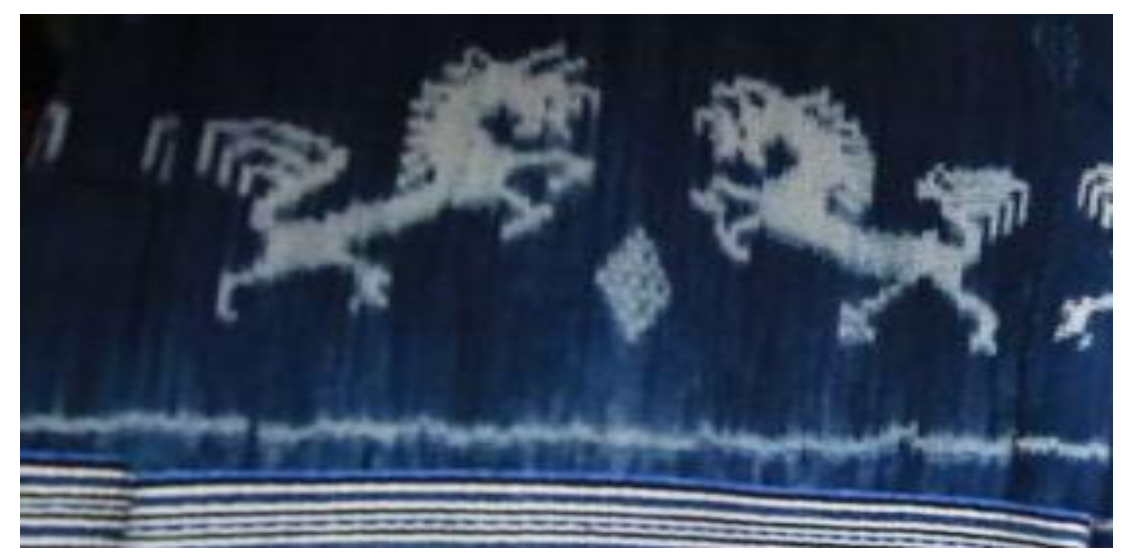

Gambar 4. Motif Kuda

\section{4) Motif Bebek}

Bebek merupakan hewan peliharaan masyarakat Sumba. Bebek mempunyai makna tertentu secara budaya sehingga dijadikan sebagai motif kain.

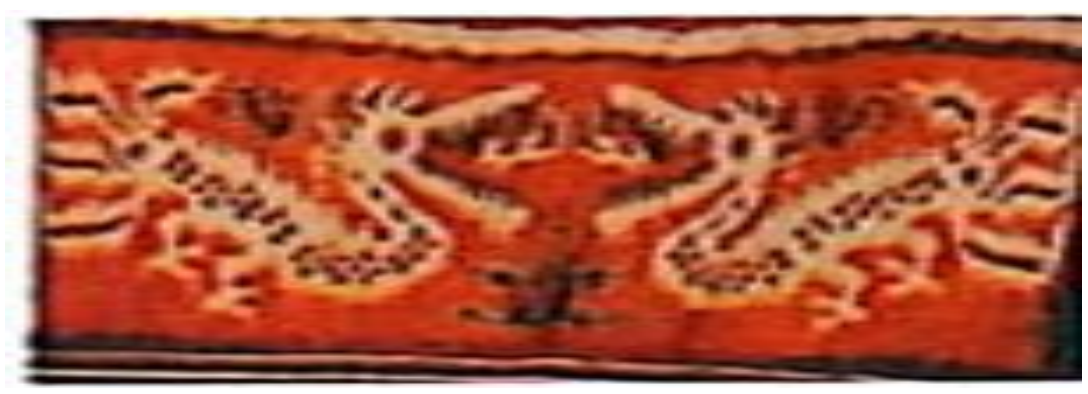

Gambar 5. Motif Bebek

\section{5) Motif Monyet}


Monyet atau kera sering dijumpai dihutan-hutan kecil di Sumba dan termasuk hewan yang dilindungi. Hewan jenis ini banyak dijumpai di hutan dan sebagai salah satu fauna yang sangat familiar bagi masyarakat Sumba.

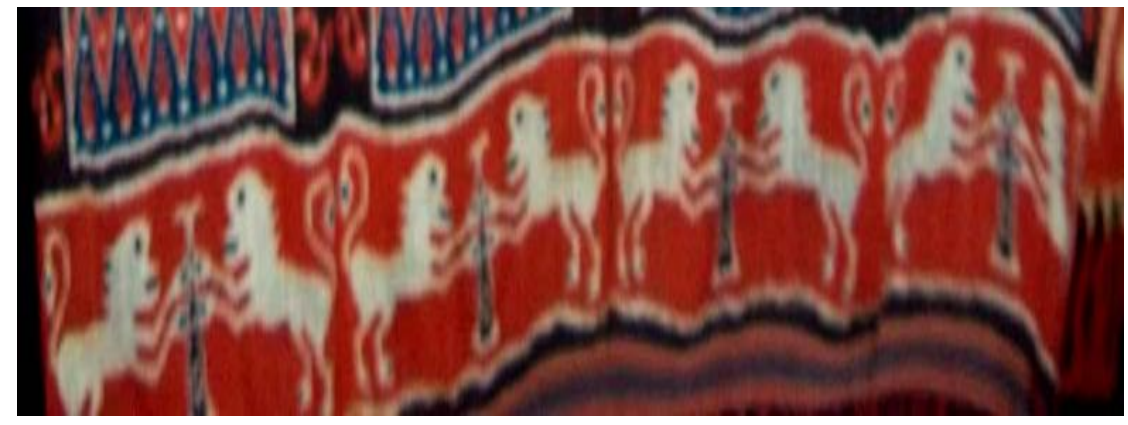

Gambar 6. Motif Monyet

\section{6) Motif Kepiting}

Kepiting merupakan hewan laut yang sering dijumpai dipulau Sumba disaat air laut surut. Kepiting sering diburuh oleh masyarakat untuk dikonsumsi atau dijual.

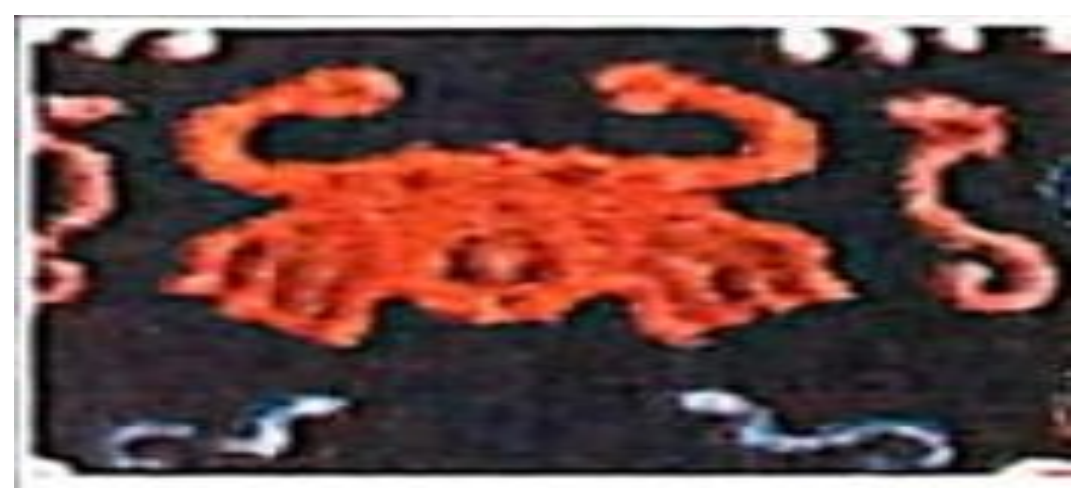

Gambar 7. Motif Kepiting.

\section{7) Motif Kerbau}

Kerbau merupakan binatang peliharan masyarakat pulau Sumba. Kerbau bernilai ekonomis dan budaya bagi masyarakat setempat, selain itu kerbau juga dijadikan sebagai belis (mahar) bagi calon pengantin wanita sampai sekarang. 


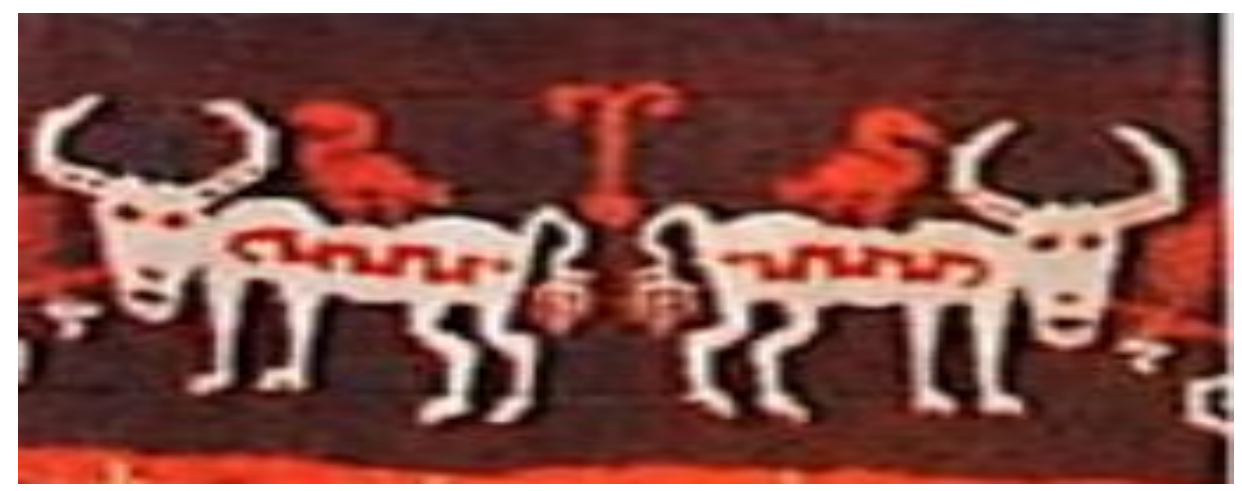

Gambar 8. Motif Kerbau

\section{8) Motif Ular}

Ular merupakan hewan malata yang sering dijumpai disekitar tempat tinggal masyarakat Sumba sperti disawah dan dihutan kecil. Belum ada catatan jumlah atau jenis ular yang hidup didaratan Sumba. Pada motif kain digambarkan ularnya bertanduk dan mempunyai kaki. Beberapa nara sumber menyebut sebagai motif naga.

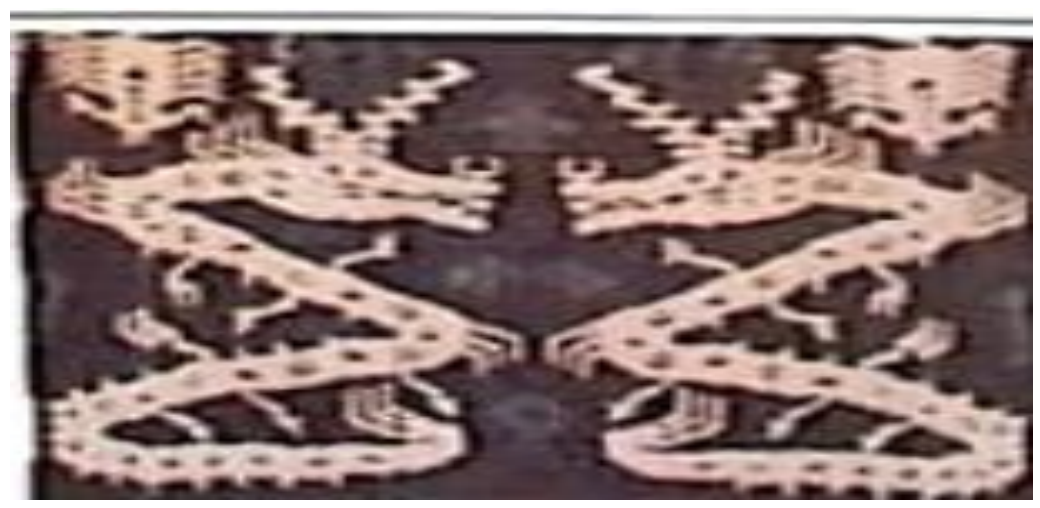

Gambar 9. Motif Naga atau ular

\section{9) Motif Singa}

Singa bukanlah binatang yang hidup dipulau Sumba, akan tetapi singa dijadikan sebagai motif kain karena pola interaksi antara penenun ataun masyarakat dengan para pedagang cina kala itu. Akan tetapi motif singa dapat dijadikan sebagai media 
pembelajaran karena termasuk hewan yang dilindungi di Indonesia yang walaupun habitatnya bukan dipulau Sumba.

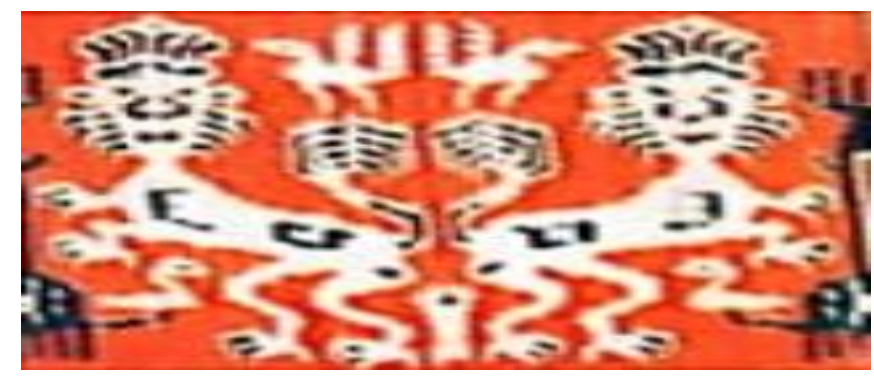

Gambar 10. Motif Singa

\section{0) Motif burung Pipit}

Burung pipit sering dijumpai didaratan Sumba seperti dikebun atau diladang-ladang dan merupakan habitat yang baik bagi burung Pipit.

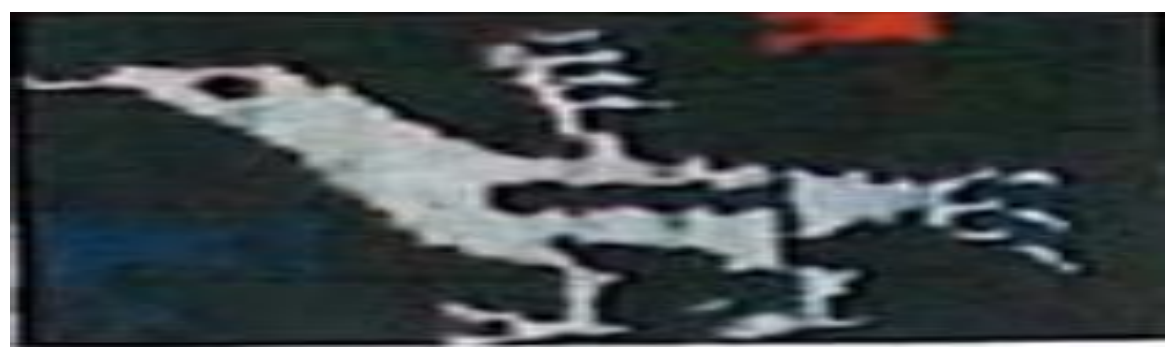

Gambar 11. Motif Burung Pipit

\section{1) Motif burung Merak}

Motif burung merak dibawah oleh para pedagang dari Timor tengah. Menurut sejarah dicatat pedagang dari Arab menginjakkan kaki dipulau Sumba pada saat penjajahan Belanda. Burung merak merupakan hewan yang dilindungi di Indonesia sehingga dapat dijadikan sebagai media pembelajaran. 


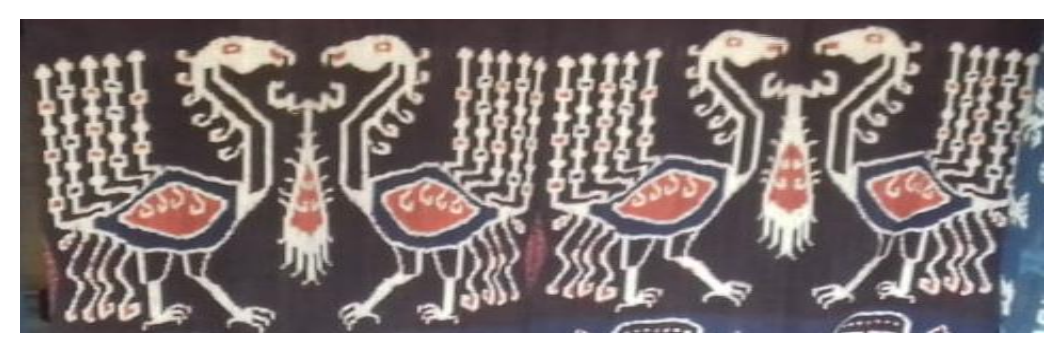

Gambar 12. Motif Burung Merak

\section{2) Motif Burung Kaka Tua}

Burung kaka tua dapat dijumpai dihutan-hutan ataupun disekitar pemukiman masyarakat Sumba. Dua atau tiga jenis burung kaka tua yang ada di Pulau Sumba

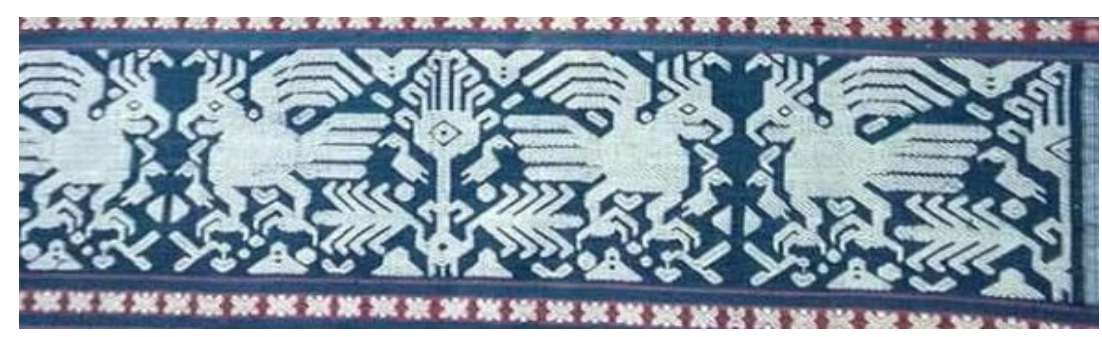

Gambar 13. Motif Burung Kaka Tua

\section{3) Motif Burung Nuri}

Burung nuri merupakan hewan yang dilindungi dipulau Sumba. Burung nuri dapat dijumpai di hutan kecil ataupun dikebunkebun masyarakat.

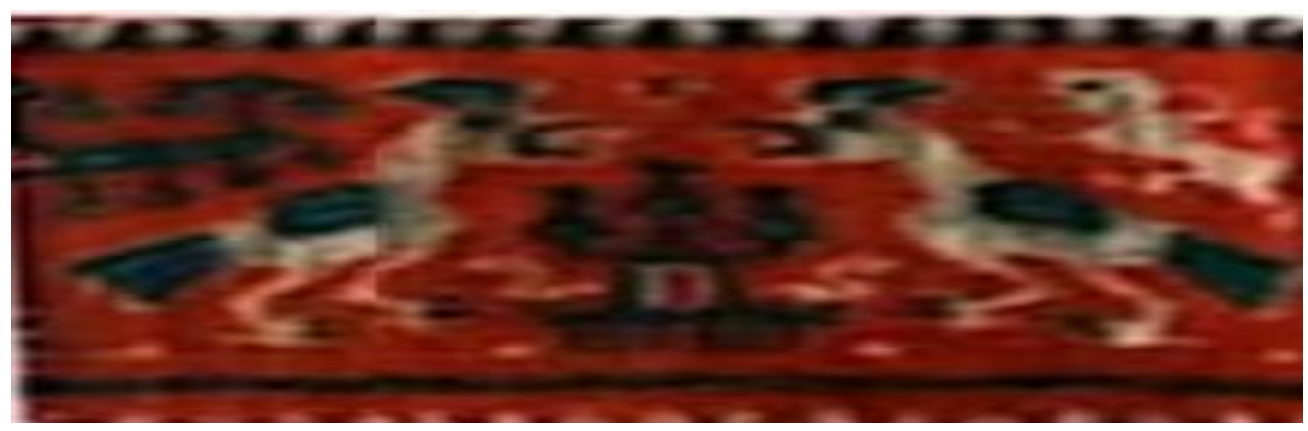

Gambar 14. Motif Burung Nuri 


\section{4) Motif Buaya}

Buaya sering dijumpai disungai kecil atau dimuarah dipulau Sumba. Walaupun buaya sebagai binatang buas tapi secara budaya mempuyai makna tersendiri, sehingga dijadikan sebagai motif kain.

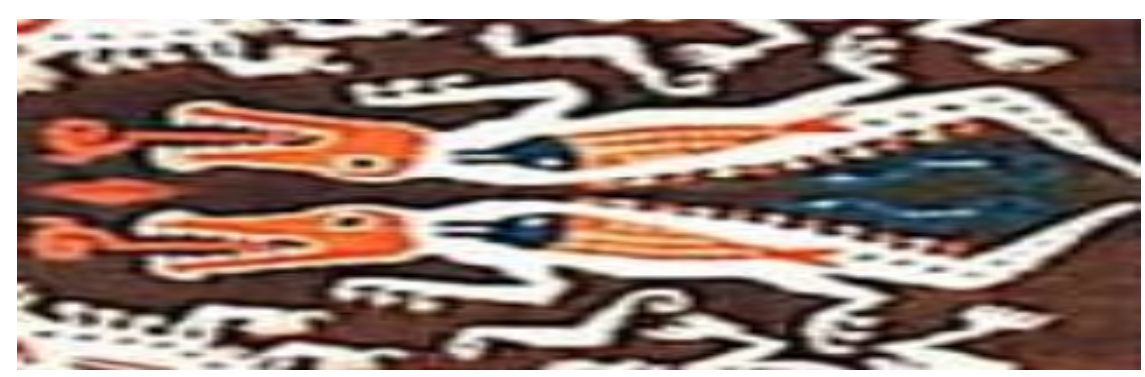

Gambar 15. Motif Buaya

\section{5) Motif Rusa}

Rusa merupakan hewan yang pernah ada dipulau Sumba. Akibat diburuh oleh orang-orang yang tidak bertanggung jawab sehingga tidak dapat dijumpai lagi saat ini. Akan tetapi rusa dapat dijadikan sebagai media pembelajaran karena termasuk binatang yang dilindungi di Indonesia.

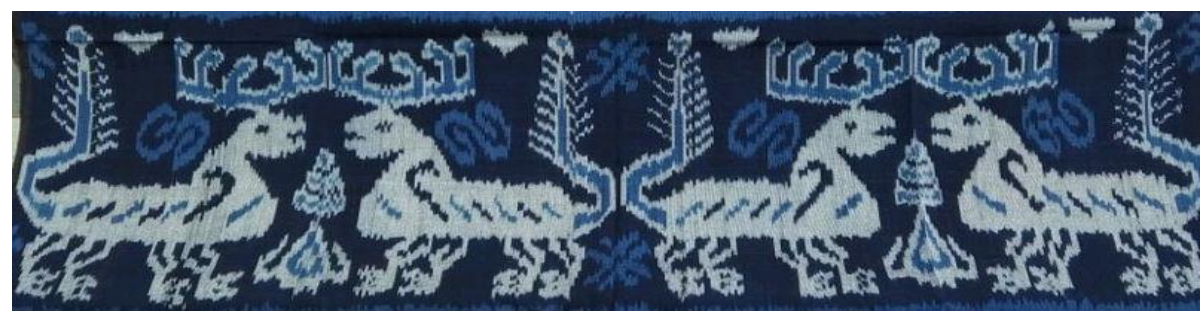

Gambar 16. Motif Rusa

\section{6) Motif Ayam}

Ayam merupakan hewan peliharaan masyarakat Sumba. Selain bernilai ekonomi juga bernilai budaya. Ada pula ayam hutan. Ayam hutam termasuk hewan yang dilindungi. 


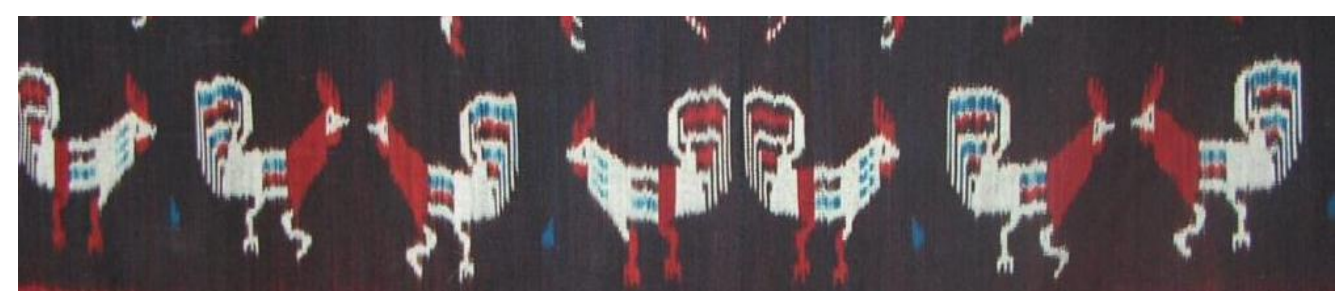

Gambar 17. Motif Ayam

\section{7) Motif Ikan}

Ikan merupaka salah satu motif yang dipumpai di Sumba. ikan sendiri bernilai ekonomi dan budaya bagi masyarakat Sumba.

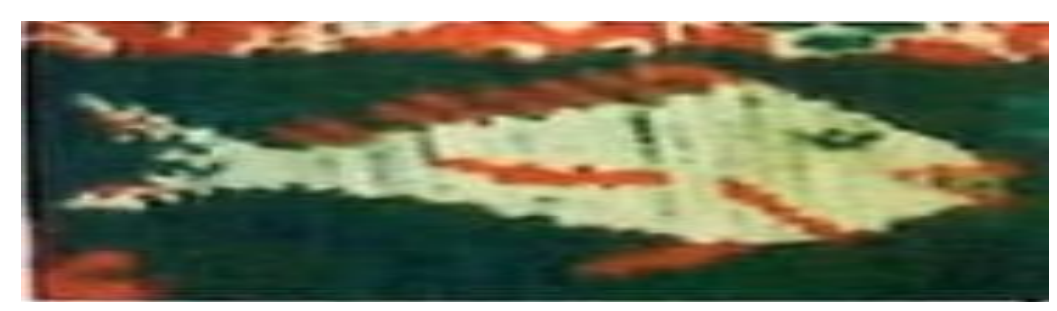

Gambar 18. Motif Ikan

\section{8) Motif Cumi}

Cumi merupakan merupan binatang laut yang diburuh oleh masyarakat pesisir pulau Sumba untuk dikonsumsi ataupun dijual.

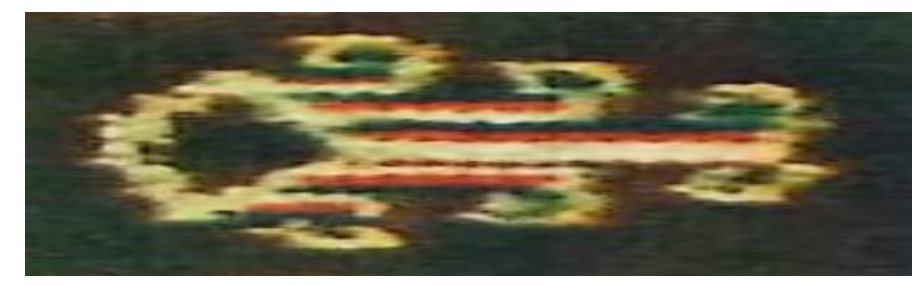

Gambar 19. Motif Cumi

\section{9) Motif Gajah}

Motif gajah dibawah oleh para pedagang dari Cina. Motif gajah mempunyai arti tersendiri secara budaya. Akan tetapi gajah dapat 
dijadikan sebagai media pembelajaran karena termasuk hewan yang dilindungi di indonesia.

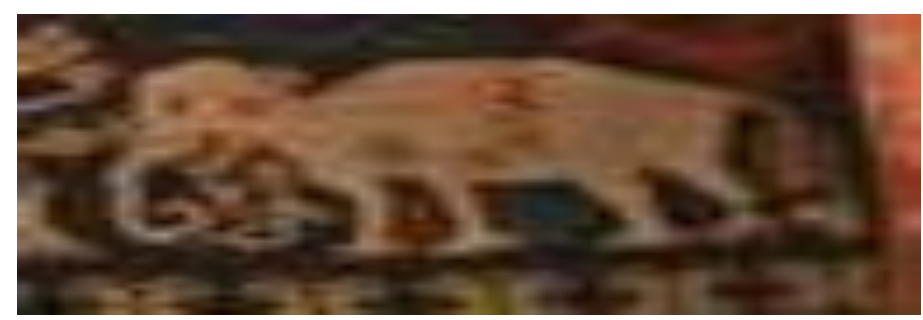

Gambar 20. Motif Gajah.

\section{0) Motif Kupu-kupu}

Kupu-kupu merupakan hewan yang dijadikan sebagai motif. Kupu-kupu hidup bebas di padang-padang pulau Sumba

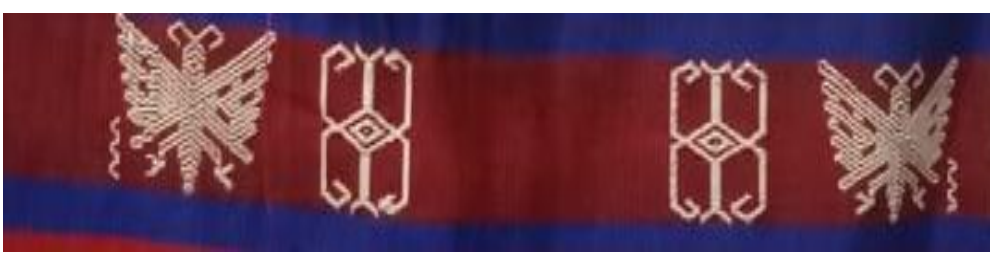

Gambar 21.motif Kupu-kupu

\section{1) Motif Bunga Jagung}

Jagung merupakan makan pokok masyarakat Sumba. Pada kain tenun digambarkan bunga dari jagung tersebut.

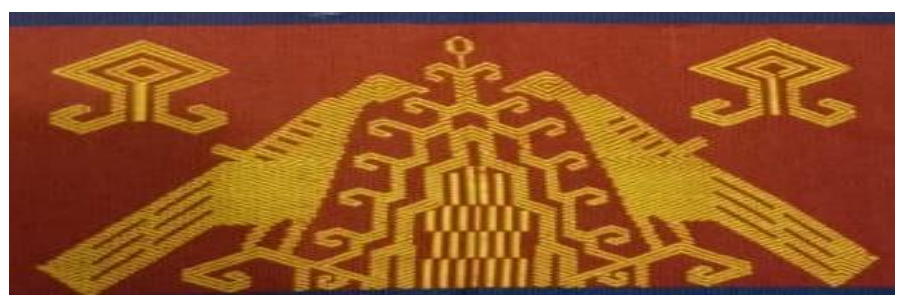

Gambar 22 Bunga Jagung yang diapit oleh burung pipit. 


\section{2) Motif Daun Bambu}

Bambu merupakan pohon yang tumbuh sumbur dipulau Sumba. Bambu sebagai bahan pembuatan rumah atau keperluan lainnya. Pada kain tenun daun dari pada bambu yang dijadikan sebagai motif.

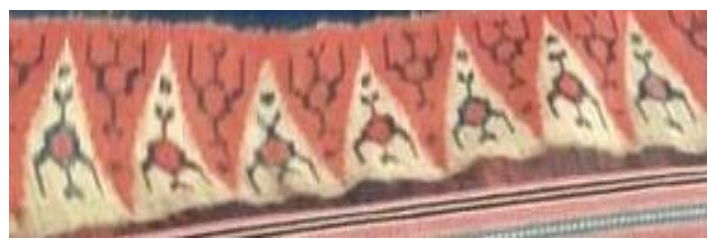

Gambar 23. Motif daun Bambu

\section{3) Motif Patola}

Blustru/belustru/petola adalah tumbuhan merambat sejenis mentimun, buah yang masih muda dapat diolah menjadi sayur, kulit buah yang tua dapat dijadikan spons. Pada kain tenun irisan buah atau bentuk spons dari patola yang dijadikan sebagai motif.

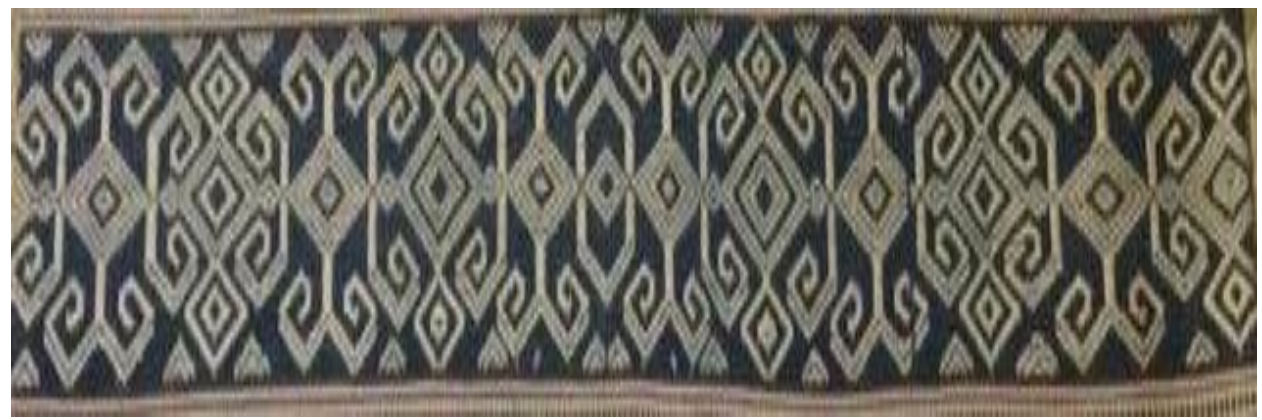

Gambar 24. Motif Irisan Buah Patola

\section{4) Motif Pohon}

Pada kain tenun, tidak dideskripsikan pohon tertentu yang dijadikan sebagai motif. Akan tetapi pohon cendana merupakan pohon yang dilindungi dipulau Sumba. Sedangkan pohon yang bernilai ekonomi adalah pohon kopi, kemiri, cengkeh, coklat, dan pohon produktif lainnya. Motif pohon tersebut dapat dijadikan 
sebagai saran untuk menjelaskan pohon-pohon yang terdapat disekitar peserta didik.

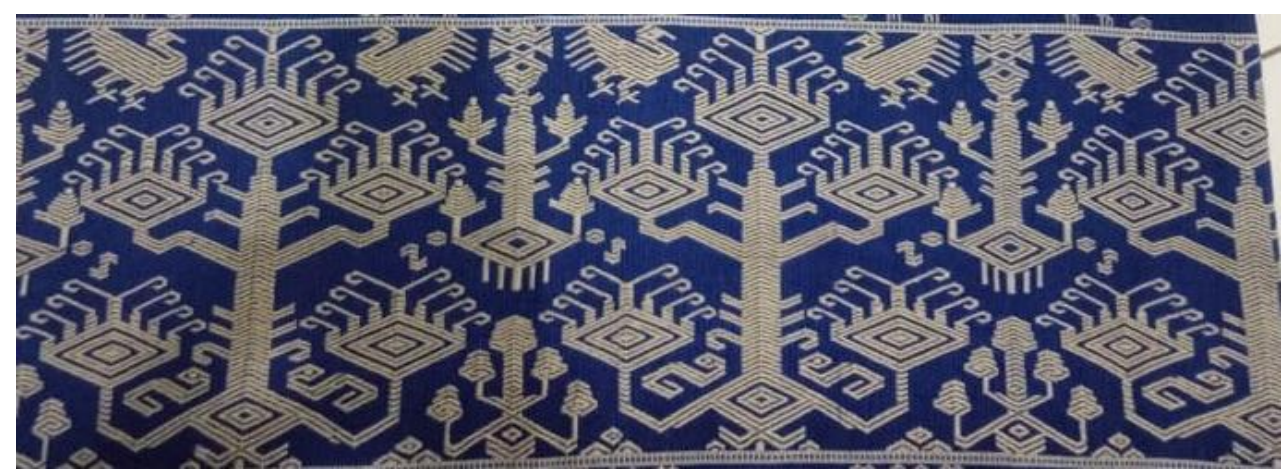

Gambar 25. Motif Pohon yang dihinggapi burung.

Memanfaatkan motif fauna dan flora yang terdapat pada kain tenun ikat Sumba dapat dikenal dengan pendidikan etnopedagogi atau pendidikan berbasis kebudayaan. Menurut Alwasilah, dkk (2009), etnopedagogi adalah pendidikan berbasis kearifan lokal yang mencakup berbagai bidang. Burger (1968:21) membagi etnopedagogi menjadi dua kata, yaitu etno yang berarti budaya dan lintas budaya, dan pedagogi yang berarti kesenian, ilmu, atau profesi mengajar. Lebih lanjut, Burger menyatakan bahwa mengajar adalah bagian besar dari motivasi dan penanaman. Burger juga menyatakan bahwa banyak kegiatan yang terkait erat dalam budaya, seperti berjualan, melakukan propaganda politik, memimpin rapat, dan lain-lain yang tidak dapat dipisahkan dari pendidikan (Burger, 1968:8).

Pemanfaatan budaya sebagai sumber belajar sangat penting untuk diterapkan guru dalam pembelajaran yang bermanfaat untuk meningkatkan pengetahuan dan pemahaman peserta didik serta sebagai media untuk penanaman rasa cinta terhadap kearifan lokal di daerahnya, penanaman karakter positif sesuai 
nilai luhur kearifan lokal serta membekali siswa untuk menghadapi segala permasalahan diluar sekolah (Pingge, 2017:134).

Pemanfaatan budaya budaya lokal dalam hal ini pakaian tradisional dapat diperkuat dari kajian yang dilakukan oleh Sari (2018). Sari mengkaji muatan materi yang terkandung dalam batik gedhog sebagai sumber belajar berbasis etnopedagogi di sekolah dasar dan mengetahui bagaimana integrasi muatan materi etnopedagogi ke dalam pembelajaran terpadu di sekolah dasar yang sesuai dengan pembelajaran abad ke 21. Hal ini sejalan dengan hasil dari penelitian Sari (2018) bahwa batik gedhog memuat beberapa aspek seperti Matematika, IPS, IPA, Agama, Bahasa Indonesia, dan PPKn. Sari (2018) memaparkan temuan materi tersebut dengan diintegrasikan dalam pembelajaran yang dapat diterapkan di SD berdasarkan KD yang ada dan dapat dikembangkan menjadi beberapa model pembelajaran sesuai Kurikulum 2013 yaitu Webbed dan Connect.

Sejalan dengan gagasan tersebut, maka penggunaan motif kain ikat Sumba juga dapat meningkatkan kualitas pembelajaran IPS di sekolah dasar. Hasil penelitian senada dengan pendapat Sudrajat (2014) bahwa penggunaan motif kain ikat Sumba juga dapat meningkatkan kualitas pembelajaran IPS di SD, dimana peserta didik di lain daerah dapat mengenal budaya dan kearifan lokal Sumba Timur melalui motif kain ikat. Dalam konteks tersebut pendidikan multi-kultural dapat terlaksana dengan baik dan berkualitas.

\section{Simpulan}

Pakaian tradisional dapat dijadikan sebagai sumber belajar IPS sekolah dasar khususnya materi keragaman budaya. Pemanfaatan pakaian adat sebagai salah satu budaya lokal merupakan bentuk 
pembelajaran kontekstual yang sarat dengan transmisi nilai dan budaya tradisional. Penggunaan kain ikat diharapkan meningkatkan kualitas pembelajaran IPS di sekolah dasar. Dalam memanfaatkan budaya atau kearifan lokal di lingkungan peserta didik, tentunya membutuhkan kreativitas dan inovasi guru IPS sehingga pembelajaran dapat berlangsung dengan menyenangkan.

Hasil kajian yang dilakukan bahwa untuk mengajarkan materi persebaran fauna dan flora di Indonesia dapat meng-gunakan motif kain tenun ikat Sumba sebagai media belajar IPS di sekolah dasar. Hal tersebut akan memudahkan peserta didik dalam memahami materi tersebut dengan baik. Di samping itu peserta didik diajarkan secara tidak langsung untuk menghargai hasil atau unsur kebudayaan yang dimilikinya sebagai identitas.

\section{Referensi}

Alwasilah, Suryadi, \& Karyono. (2009). Etnopedagogi: Landasan praktek dan pendidikan guru. Bandung : PT Kiblat Buku Utama.

Apa pengertian dari pakaian adat. Dari https://brainly.co.id/tugas/32327. diakses 14 Februari 2020

Bili., F. M.; Sujadi. A., \& Arigiyati. T.A. (2019). Identifikasi etnomatematika pada motif kain tenun Sumba Barat Daya. UNION: Jurnal Pendidikan Matematika. 7, (1), 115-124.

Burger, H. G. (1968). Ethno-pedagogy: A manual in cultural sensitivity with techniques for improving cross teaching by fitting ethnic patterns. New Mexico: Soouthwestern Cooperative Educational Laboratory INC.

Depdikbud. (1990). Pakaian adat tradisonal daerah Propinsi Nusa Tenggara Timur. Jakarta: Depertemen P dan K

Fanpula, T, S. (2014). Penjelasan Pasal 32 UUD 1945 dari https://www.limc4u.com/blog/penjelasan-pasal-32-uud1945-3/ diakses 14 Februari 2020

Hebi, F. (2014). Motif dan makna pada kain ikat Sumba Timur. Tersedia pada laman: 
maxfmwaingapu.com/2014/11/semiotik-motif-dan-maknapada-kain-ikat-sumba-timur/ diakses 11 Desember 2019

Mamulak, N. R. (2015). Rancang bangun sitem informasi motifmotif tenunan daerah Nusa Tenggara Timur menggunakan pendekatan unified proces. Proceeding Seminar Nasional Teknologi Informasi dan Komunikasi 2015 (SENTIKA 2015) ISSN: 2089-9815 Yogyakarta, 28 Maret 2015.

Ndima, P. P. (2007). Kajian budaya kain tenun ikat Sumba Timur. Salatiga: Nuansa Sukses.

Pakaian adat dari https://id.wikipedia.org/wiki/Pakaian_adat. diakses 14 Februari 2020.

Pingge, H. D. (2017). Kearifan lokal dan penerapannya di sekolah. Jurnal Edukasi Sumba, 1, (2), 28-136.

Pingge, H.D. (2019). Learning materials based on local wisdom of Sumbanese as the source of learning in elementary school. Proceedings the 4th International Seminar on Social Studies and History Education (ISSSHE). Bandung: UPI

Sari, R.N. (2018). Batik Gedhog desa Kedungrejo, Tuban, sebagai sumber belajar berbasis etnopedagogi di sekolah dasar. JPGSD, 06 (10), 1769-1780.

Soelarto, B. (1979) Budaya Sumba. Jakarta: Proyek Pengembangan Media Kebudayaan DITJEN Kebudayaan Departemen P \& K Republik Indonesia.

Spradley, P.J. (2007). Metode etnografi. Yogyakarta: Tiara Wacana.

Sudrajat, (2014) Pendidikan multikultural untuk meningkatkan kualitas pembelajaran IPS di sekolah dasar, JIPSINDO, 1, (1), 1-19.

Sudrajat, Wulandari, T; \& Wijayanti, A.T. (2015). Muatan nilai karakter melalui permainan tradisional di PAUD Amongsiwi, Panggungharjo, Sewon, Bantul, JIPSINDO, 2, (1), 44-65.

Sugiyono. (2009). Metode Penelitian Pendidikan. Bandung: Penerbit Alfabeta.

Supardi, Widiastuti, A., \& Saliman (2015) Pengembangan media pembelajaran IPS Terpadu berbasis Audio-visual. JIPSINDO, 2, (1), 1-21. 